\title{
Fabrication of chitosan microparticles loaded in chitosan and poly(vinyl alcohol) scaffolds for tissue engineering application
}

\author{
B R SRINIVAS MURTHY, GIRIPRASATH RAMANATHAN and \\ UMA TIRICHURAPALLI SIVAGNANAM* \\ Bioproducts Lab, CSIR-Central Leather Research Institute, Chennai 600020, India \\ *Author for correspondence (suma67@gmail.com)
}

MS received 21 May 2016; accepted 3 October 2016; published online 27 July 2017

\begin{abstract}
In recent decades, the use of microparticle-mediated drug delivery is widely applied in the field of biomedical application. Here, we report the new dressing material with ciprofloxacin-loaded chitosan microparticle (CMP) impregnated in chitosan $(\mathrm{CH})$ and poly(vinyl alcohol) (PVA) scaffold for effective delivery of drug in a sustained manner to the wound site. Moreover, the peculiar physiochemical and structural properties of the $\mathrm{CH}-\mathrm{CMP}$ scaffold has proved better tensile strength and excellent swelling to achieve $82 \%$ of drug release. In vitro biocompatibility was done for both scaffold using NIH 3 T3 fibroblasts and human keratinocytes (HaCaT) cell lines. In vitro fluorescent activity showed distinct biocompatibility with good cell adhesion and proliferation. However, the $\mathrm{CH}-\mathrm{CMP}$ scaffold showed best result to act as promising biomaterial in effective drug delivery in tissue engineering.
\end{abstract}

Keywords. Biocompatibility; tissue engineering; wound dressing; microparticle; scaffold.

\section{Introduction}

The tissue engineering approaches with development of biodegradable scaffold found suitable unless the scaffold is compatible with the cells is essential for tissue regeneration [1]. The promising biomaterial should posses several advantage properties like better biocompatibility, biodegradability and drug delivery system to act as wound-dressing material [2]. The biomaterial should mimic the function of the extracellular matrix (ECM), to make compatible material with delivery of drug from the scaffold will make more efficient in tissue engineering application [3]. Chitosan has remarkable properties such as mucoadhesive [4], biocompatibility [5], non-toxicity [6], haemostatic [7] and biodegradability [8]. Moreover, it is widely used as a carrier of drug to attain a biodegradable drug delivery system [9]. Poly(vinyl alcohol) (PVA) is a more susceptible synthetic water soluble polymer and has excellent film forming and adhesive property for application as scaffold in biomedical application [10]. Ciprofloxacin is a well-known topical antibacterial agent that acts effectively in recent wound management era. Ciprofloxacin HCL is a second-generation fluroquinolone, kills both Gram-positive and Gram-negative bacteria effectively [11]. One of the potential techniques is to entrap the bioactive molecule per drug into the microparticle because it has advantages of extended shelf life and generally a higher drug-carrying ability [12]. The drug-loaded mucoadhesive microparticle was impregnated into the scaffold for sustained delivery at the active site for extended period of time. By this impregnation of microparticle, scaffold finds usefulness due to the degradability, efficiency of drug delivery in tissue engineering $[13,14]$. The combination of microparticle with both natural and synthetic scaffolds acts as co-passenger for the sustained release of drug by improving and thereby increasing the biocompatibility with prevention of infection from wound site. Moreover, the benefits of incorporating active drug in a polymer matrix increase the protection from the surrounding medium or processing conditions and their controlled release behaviour of the drug $[14,15]$. Sustained drug delivery provides advantages of the scaffold because it acts as milieu biocompatible carrier to get rid of wound infection and to achieve better patient compliance [16].

Comparative study on characterization of chitosan $(\mathrm{CH})$ and PVA developed scaffold arises especially to have wounddressing material with sustained drug release. Therefore, the aim of the present work was to load ciprofloxacin into the chitosan microparticle (CMP) to make efficient delivery of drug on the wound site to prevent infection. The drug-loaded CMP was impregnated into the prepared chitosan ( $\mathrm{CH}-\mathrm{CMP})$ and poly(vinyl alcohol) (PVA-CMP) scaffolds by a solution casting method, and to study the physiochemical, mechanical and biological properties of the developed material/wound dressing with drug delivery in tissue engineering that has to be reasonably affordable by the common man. 


\section{Materials and methods}

\subsection{Materials}

$\mathrm{CH}$ (low molecular weight), PVA, sodium tri-poly phosphate, ciprofloxacin HCL, Dulbecco's modified Eagle's medium (DMEM), foetal bovine serum (FBS) and the supplementary antibiotics for tissue culture were purchased from Sigma Aldrich, India. The mouse NIH 3T3 fibroblast and human $(\mathrm{HaCaT})$ keratinocyte cell line were obtained from the National Centre for Cell Science (NCCS), Pune, India.

\subsection{Method}

2.2a Preparation of biopolymeric CMP: Chitosan solution was prepared by dissolving chitosan in $1 \%(\mathrm{w} / \mathrm{v})$ acetic acid solution. To the $25 \mathrm{ml}$ of chitosan solution, $5 \mathrm{ml}$ of $0.1 \mathrm{M}$ sodium tri-poly phosphate was added and were mixed thoroughly. Sun flower oil $(50 \mathrm{ml})$ and $2 \mathrm{ml}$ of Tween- 80 were added and kept under mechanical stirrer. To this, well mixed polymer solution taken in the $50 \mathrm{ml}$ syringe was added slowly drop-wise and maintained in a stirring for $3 \mathrm{~h}$. After stirring, it is subjected for centrifugation at $3000 \mathrm{rpm}$ for $20 \mathrm{~min}$ followed by filtration. The prepared $\mathrm{CH}$ microparticles were washed with hexane, toluene, ethanol, acetone and petroleum ether until free from oil phase. Finally, the microparticles were collected and dried under room temperature for $24 \mathrm{~h}$. Drugloaded CMP was prepared by mixing $500 \mathrm{mg}$ of ciprofloxacin HCL dissolved in $1 \mathrm{ml}$ of distilled water and were added spontaneously to the polymer solution and rest of the procedure was followed as mentioned above [17].

2.2b Preparation of CMP-impregnated scaffolds $(\mathrm{CH}-\mathrm{CMP}$ and PVA-CMP): The $\mathrm{CH}$ and PVA scaffolds were prepared by using solvent casting method. Here $1 \% \mathrm{CH}$ and $2 \%$ PVA solutions were prepared by dissolving in double-distilled water, and to this $50 \mathrm{mg}$ of drug-loaded CMP were added and the homogenization was continued for another $30 \mathrm{~min}$. Finally, the mixture was poured into the polyethylene tray (measuring $12 \mathrm{~cm} \times 10 \mathrm{~cm}$ ) and dried at room temperature to get $\mathrm{CH}-\mathrm{CMP}$ and PVA-CMP scaffolds [18].

\subsection{Physico-chemical characterization}

2.3a FTIR spectroscopy: Fourier transform infrared (FTIR) measurements were carried out to determine the formation and changes in the functional groups of the prepared $\mathrm{CH}-$ CMP and PVA-CMP scaffolds. The spectra were measured at a resolution of $4 \mathrm{~cm}^{-1}$ in the frequency range of 4000$600 \mathrm{~cm}^{-1}$ using ABB 3000 spectrometer with Grams as the operating software $[19,20]$.

2.3b Thermal analysis: The prepared $\mathrm{CH}-\mathrm{CMP}$ and PVACMP scaffolds were subjected to thermogravimetric analysis using universal V4.4A TA instruments. Three milligrams of the sample was heated at $10^{\circ} \mathrm{C} \mathrm{min}^{-1}$ at a temperature range of $0-800^{\circ} \mathrm{C}$ using $\mathrm{Al}_{2} \mathrm{O}_{3}$ crucibles. Differential scanning calorimetry (DSC) measurements were taken using the V4.4A Universal instrument from 0 to $300^{\circ} \mathrm{C}$ at a heating rate of $10^{\circ} \mathrm{C} \mathrm{min}^{-1}$ under nitrogen atmosphere using $3 \mathrm{mg}$ of the sample [21].

2.3c SEM and particle size: CMP, CH-CMP and PVACMP scaffolds were mounted on brass studs and was goldcoated using ion coater (Emitech brand). The surface morphology was visualized using scanning electron microscope (SEM) (VEGA3 SBH TESCAN) operating at an accelerating voltage of $5-20 \mathrm{kV}$ [21]. The mean particle size was measured by particle size analyzer (Malvern Instruments $3000 \mathrm{SH}, \mathrm{UK}$ ).

\subsection{Tensile strength}

Three dumb-bell shaped specimens of the composite scaffolds $\left(100 \times 16 \mathrm{~mm}^{2}\right)$ were prepared and load-elongation measurement was carried out at a crosshead speed of $5 \mathrm{~mm} \mathrm{~min}^{-1}, 25^{\circ} \mathrm{C}$ temperature and relative humidity of $65 \%$, respectively. Percentage of elongation at break was measured using a universal testing machine (INSTRON model 1405) according to Vogel at an extension rate of $5 \mathrm{~mm} \mathrm{~min}^{-1}$ [18].

\subsection{Swelling study}

The prepared $\mathrm{CH}, \mathrm{PVA}, \mathrm{CH}-\mathrm{CMP}$ and PVA-CMP scaffolds were cut into square pieces $\left(10 \times 10 \mathrm{~mm}^{2}\right)$ and immersed in a phosphate buffer solution (PBS, $\mathrm{pH}$ 7.4) at room temperature until the film reached a constant size. The equilibriumswelling ratio was calculated by the following equation:

$$
\text { Swelling }(\%)=\frac{W_{1}-W_{0}}{W_{0}} \times 100 \text {, }
$$

where $W_{0}$ and $W_{1}$ are the initial and final weights of the film, respectively [22].

\subsection{In vitro degradation studies}

$\mathrm{CH}, \mathrm{PVA}, \mathrm{CH}-\mathrm{CMP}$ and PVA-CMP scaffolds were cut into dimensions of $2 \times 2 \mathrm{~cm}^{2}$ for in vitro degradation studies. The cut specimens were placed in sealed petriplates containing phosphate buffer solution (PBS, $\mathrm{pH}$ value $7.4 \pm 0.05$ ) and were agitated and incubated in vitro at a temperature of $37.0 \pm 0.1^{\circ} \mathrm{C}$ and $100 \mathrm{rpm}$ from 1 st week to 4 th week. Three specimens were recovered at the end of each week and the scaffolds were freeze-dried and then weighed. The percentage of degradation was calculated using the following equation [23]:

$$
\text { Degradation }(\%)=\frac{W_{\mathrm{i}}-W_{\mathrm{f}}}{W_{\mathrm{i}}} \times 100,
$$

where $W_{\mathrm{i}}$ and $W_{\mathrm{f}}$ are the initial and final weights of the scaffold, respectively. 


\subsection{In vitro drug release study}

Ciprofloxacin release from the $\mathrm{CH}-\mathrm{CMP}$ and PVA-CMP scaffolds was determined by placing the scaffold in Franztype diffusion cell at $37^{\circ} \mathrm{C}$. The receiver compartment was filled with PBS (pH 7.4), at specific interval, $1 \mathrm{ml}$ of buffer was removed from the receiver compartment and replaced with an equal quantity of phosphate buffer to maintain a constant volume and the whole setup was stirred using magnetic stirrer. The ciprofloxacin content in the samples was determined by measuring the absorbance at $272 \mathrm{~nm}$ (Shimadzu UV 1800 ver. 2.43). The percentage of ciprofloxacin released from the scaffolds was determined using the following equation [23]:

$$
E=\frac{Q_{\mathrm{p}}}{Q_{\mathrm{t}}} \times 100
$$

where $E$ is the percentage of drug release from $\mathrm{CH}-\mathrm{CMP}$ and PVA-CMP, $Q_{\mathrm{p}}$ the quantity of drug release and $Q_{\mathrm{t}}$ the total quantity of ciprofloxacin loaded in the scaffold [23].

\subsection{Porosity}

Porosity of the prepared samples was achieved by the liquid displacement method. Ethanol was used as a displacement liquid because of its easy penetration through the pores of the samples [18]. A known weight $(W)$ of the sample was immersed in known volume $(V 1)$ of ethanol. A series of brief evacuation and re-pressurization cycles were conducted and repeated until the air bubbles stopped forming. The total volume of ethanol and ethanol-impregnated samples was then recorded as $V 2$. The samples impregnated in ethanol were removed from the cylinder was recorded as $V 3$. The percentage of porosity was obtained using:

$$
\text { Porosity }(\%)=(V 1-V 3 / V 2-V 3) \times 100 \text {. }
$$

\subsection{Biological properties}

A monolayer of the NIH 3 T3 fibroblast cell line was grown on $\mathrm{CH}, \mathrm{PVA}, \mathrm{CH}-\mathrm{CMP}$ and PVA-CMP scaffolds and cell viability of the scaffolds was performed using MTT assay. The NIH3T3 fibroblast cell line were grown on the scaffolds placed in 24-well plates (Corning, NY) and maintained in DMEM with $10 \%$ foetal calf serum supplemented with penicillin $\left(120 \mathrm{U} \mathrm{ml}^{-1}\right)$, streptomycin $\left(75 \mathrm{mg} \mathrm{ml}^{-1}\right)$, gentamycin $\left(160 \mathrm{mg} \mathrm{ml}^{-1}\right)$ and amphotericin $\mathrm{B}\left(3 \mathrm{mg} \mathrm{ml}^{-1}\right)$ at $37^{\circ} \mathrm{C}$ at a density of $5 \times 10^{4}$ cells ml ${ }^{-1}$ and then incubated for $24 \mathrm{~h}$ in a humidified atmosphere of $5 \% \mathrm{CO}_{2}$. Cells cultured in blank wells were used as control [24]. After $48 \mathrm{~h}$, the culture medium was replaced with a serumfree medium containing $10 \mu \mathrm{l}$ of 3-(4,5-dimethylthiazol-2yl)-2,5-diphenyltetrazoliumbromide (MTT) and incubated at $37^{\circ} \mathrm{C}$ for $4 \mathrm{~h}$ in a humidified atmosphere of $5 \% \mathrm{CO}_{2}$.
The medium was aspirated and then $500 \mu$ per well of dimethylsulphoxide (DMSO) was added to dissolve the formazan needles with slow agitation for 10 min to yield a bluishpurple solution. The absorbance of the dissolved solution was measured at $570 \mathrm{~nm}$ using Universal Micro plate Reader [25].

Cell attachment and proliferation of both NIH 3T3 fibroblast and human keratinocytes $(\mathrm{HaCaT})$ cell lines were quantified for live cell assay at regular time intervals $(6,12,24$ and $48 \mathrm{~h}$ ), the medium was removed and the cells were fixed with 4\% paraformaldehyde and washed with PBS for several times. Furthermore, each cell was stained with calcein AM solution $(2 \mu \mathrm{M} ; 400 \mu \mathrm{l})$ and incubated for $30 \mathrm{~min}$ at $37^{\circ} \mathrm{C}$. Then, the plates with scaffold were washed with PBS for several times and viewed at fluorescence microscope (EVOS FLoid Cell Imaging Station, Thermo Fisher Scientific, USA) [26,27].

\subsection{Antimicrobial activity}

In this study, two bacterial strains were used, including one Gram-positive bacteria Staphylococcus aureus (ATCC 11632) and one Gram-negative bacteria Escherichia coli (ATCC 10536). All bacterial cultures were subcultured and maintained aseptically. The antimicrobial activity of the scaffolds was evaluated using the modified agar well diffusion method. About $100 \mathrm{ml}$ [ $10^{5} \mathrm{CFU}$ (colony forming units)] of each bacterial culture was spread over the agar surface (Muller-Hinton agars) using a sterile glass spreader. The plates were then incubated for $24 \mathrm{~h}$ at $37^{\circ} \mathrm{C}$. The antibacterial activity was evaluated by measuring the zone of inhibition against the test organism [26].

\subsection{Statistical analysis}

All the experiments were conducted in triplicates. Results are presented as mean $\pm \mathrm{SD}(n=3)$. ANOVA (analysis of variance) and Student's $t$ test were done to determine the significant differences among the groups. The observed differences were statistically significant when $P<0.05$.

\section{Results and discussion}

\subsection{FTIR spectroscopy}

FTIR spectra of the CH-CMP and PVA-CMP are depicted in figure 1 . The $\mathrm{CH}-\mathrm{CMP}$ shows amide I and amide II absorption bands, which were most frequently seen at 1623 ( $C=O$ stretching) and $1560 \mathrm{~cm}^{-1}(\mathrm{~N}-\mathrm{H}$ in plane deformation coupled with $\mathrm{C}-\mathrm{N}$ stretching), respectively. The band at $1316 \mathrm{~cm}^{-1}$ tends to $\mathrm{CH}_{2}$ wagging coupled with $\mathrm{O}-\mathrm{H}$ in plane deformation [27]. The IR spectrum of PVA-CMP shows that the band at $1326 \mathrm{~cm}^{-1}$ was due to the coupling of the $\mathrm{O}-\mathrm{H}$ in-plane vibrations, and the band at $1432 \mathrm{~cm}^{-1}$ was the $\mathrm{C}-\mathrm{H}$ wagging vibrations. The band at $2932 \mathrm{~cm}^{-1}$ was attributed to the $\mathrm{CH}_{2}$ vibration. The band near $1083 \mathrm{~cm}^{-1}$ is due to CO stretching 


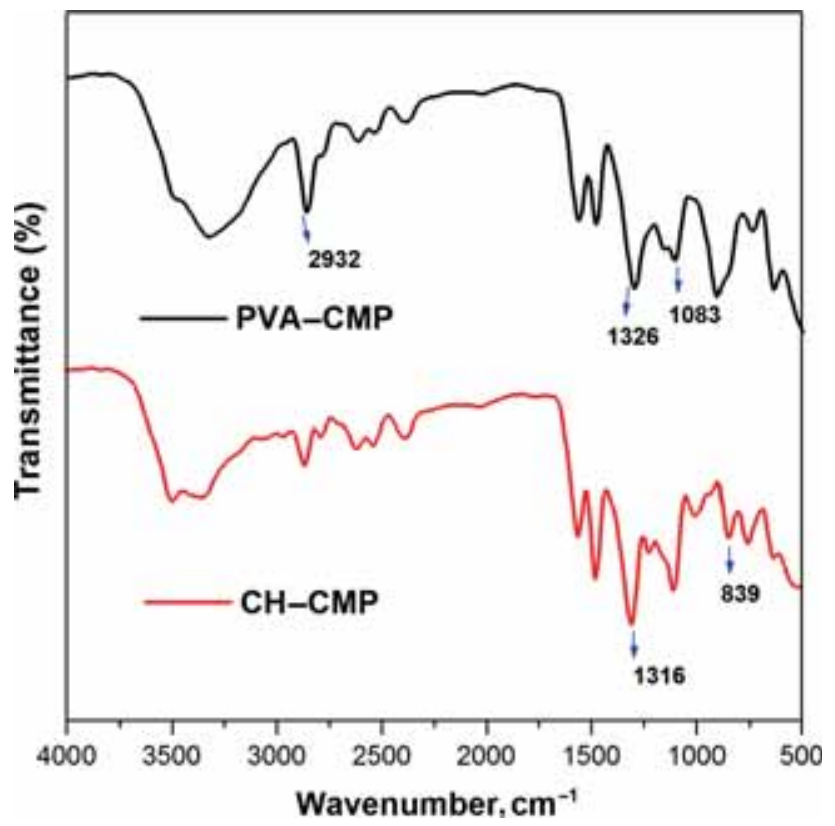

Figure 1. FTIR curves of the scaffolds.

and the peak near $2885 \mathrm{~cm}^{-1}$ is due to $\mathrm{CH}$ vibration. The absorption band at $839 \mathrm{~cm}^{-1}$ corresponds to the polysaccharide structure of $\mathrm{CH}$, which corresponds to the presence of CMP in the scaffold $[19,20]$.

\subsection{Thermal analysis}

DSC thermograms of the scaffolds are given in figure 2. The endothermic peaks at 89.91 and $106.47^{\circ} \mathrm{C}$ correspond to the denaturation temperature of the $\mathrm{CH}-\mathrm{CMP}$ and PVA-CMP, respectively. The endothermic peak shown at $205-215^{\circ} \mathrm{C}$ was due to the thermal melting temperature of the CMP in scaffold. The stability of the scaffold was mainly due to the interchain crosslinks of the polymer matrix with the $\mathrm{CH}$ microsphere. Thus, it can be inferred that CMP impregnated scaffold showed an increase in the thermal behaviour. The thermal properties of the scaffold are given in table 1 [28,29].

TGA thermograms of the scaffolds are shown in figures 3 and 4. A three-stage weight loss of the samples was observed for all the scaffolds. The first-stage weight loss was due to the loss of moisture in the scaffolds, while second and third losses correspond to the thermal decomposition of the $\mathrm{CH}$, PVA and CMP. The moisture loss over a temperature range at $60-110^{\circ} \mathrm{C}$ attributes to first-weight loss. The weight loss was more apparent from the $T_{-5 \%}$ values, which are listed in table 1. Differential thermal analysis (DTA) of the scaffold shows two $T_{\max }$ values, which are due to the degradation of the $\mathrm{CH}$ and PVA, respectively. $T_{\max 2}$ values observed were found to be responsible for the degradation of the CMP. The increase in the $T_{\max 2}$ values was due to the intermolecular hydrogen bonding of CMP to CH and PVC [21,29].

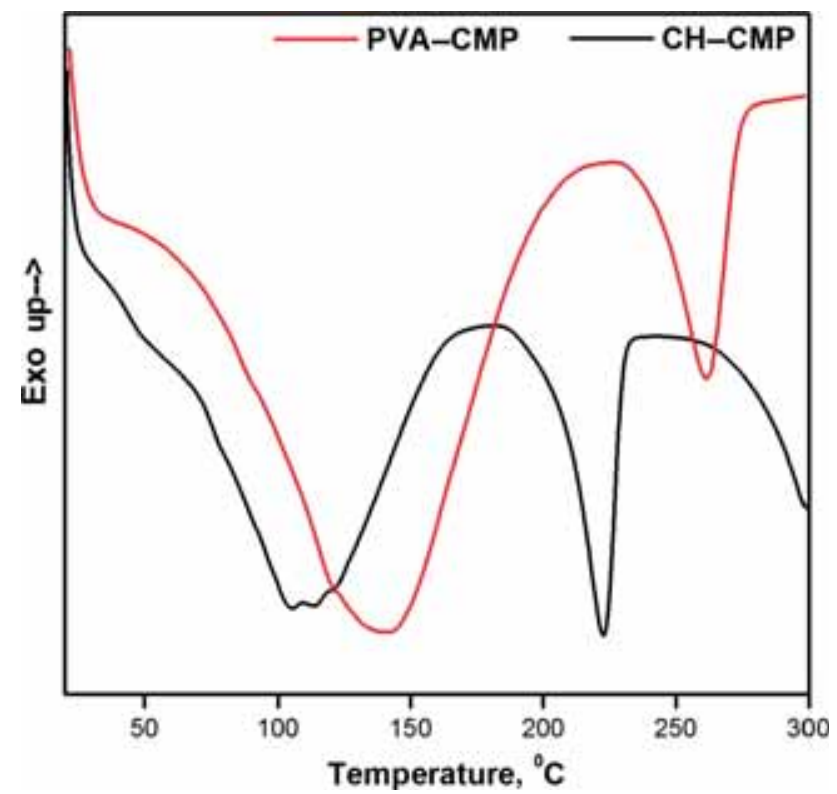

Figure 2. DSC curves of the scaffolds.

\subsection{SEM}

Surface morphology of the CMP is observed in figure 5a and $\mathrm{b}$, which has a smooth surface CMP in a spherical shape with a size range between 2 and $4 \mu \mathrm{m}$. All the CMP showed a similar morphology when incorporated into the scaffolds. The surface morphology of the CMP incorporated scaffolds are depicted in figure 5c and d micrographs as $\mathrm{CH}-\mathrm{CMP}$ and PVA-CMP. The scaffold exhibited a smooth surface, but CMP present all over the scaffold with braided nature to attain better cell adhesion in entire scaffolds [29-31]. The hydrodynamic diameter of the microparticle with slight aggregation was found and exhibited in figure 6.

\subsection{Tensile strength}

Scaffold with good mechanical property of the biomaterial should be considered by the physician to be handled onto the wound surface. The details of the tensile strength with the Young's modulus are given in table 2 . The Young's moduli of $\mathrm{CH}$, PVA, CH-CMP and PVACMP scaffolds were found as $0.44 \pm 0.03,0.39 \pm 0.06$, $0.42 \pm 0.01$ and $0.43 \pm 0.07$, respectively. There was a decrease in the Young's modulus in CH-CMP scaffold when compared to that of PVA-CMP scaffold. The CMPimpregnated scaffold with $\mathrm{CH}$ showed a low-molecular interaction between them when compared with the PVC scaffold $[18,32]$.

\subsection{Swelling studies}

CH-CMP and PVA-CMP have to achieve better swelling ratio to enhance the efficiency of biomaterial to attain good 
Table 1. Thermal properties of $\mathrm{CH}-\mathrm{CMP}$ and PVA-CMP scaffolds.

\begin{tabular}{lccccccc}
\hline Scaffold name & $T_{-5 \%}\left({ }^{\circ} \mathrm{C}\right)$ & $T_{\max 1}\left({ }^{\circ} \mathrm{C}\right)$ & $T_{\max 2}\left({ }^{\circ} \mathrm{C}\right)$ & $T_{\mathrm{d}}\left({ }^{\circ} \mathrm{C}\right)$ & $T_{\mathrm{m}}\left({ }^{\circ} \mathrm{C}\right)$ & $\Delta H_{\mathrm{m}}\left(\mathrm{Jg}^{-1}\right)$ & $\Delta H_{\mathrm{d}}\left(\mathrm{Jg}^{-1}\right)$ \\
\hline CH-CMP & 190.1 & 379.3 & 444.6 & 89.91 & 213.64 & -196.36 & -69.39 \\
PVA-CMP & 191.2 & 373.5 & 450.8 & 106.47 & 209.17 & -191.31 & -50.90 \\
\hline
\end{tabular}

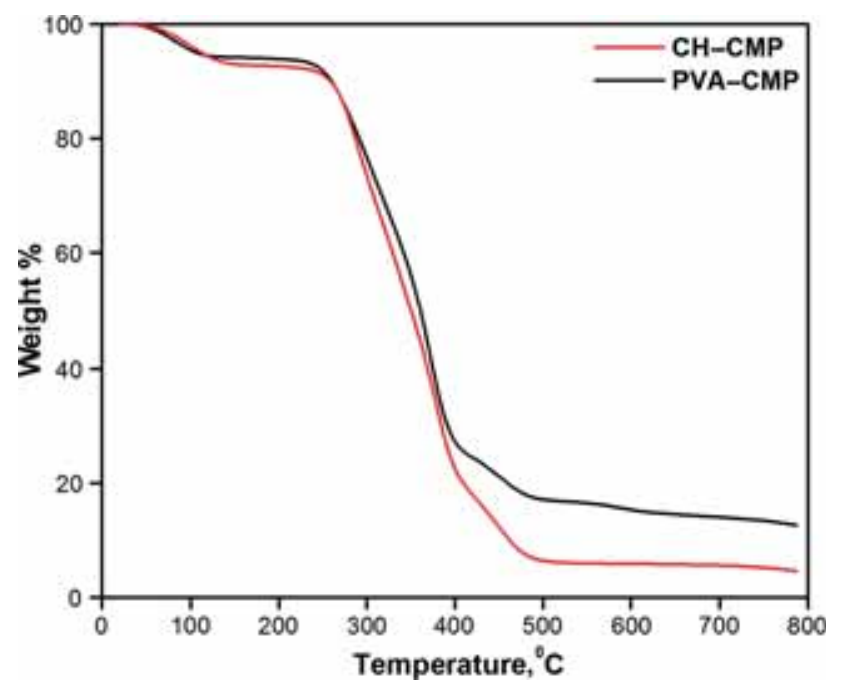

Figure 3. TGA curves of the scaffolds.

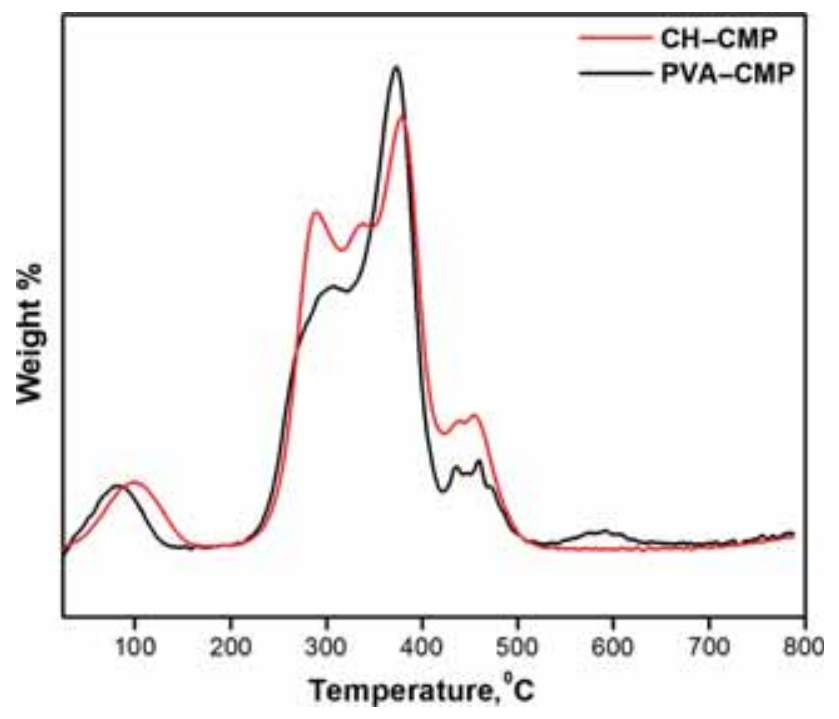

Figure 4. DTA curves of the scaffolds.

absorption of exudates from wounds, sufficient amount of oxygen supply is required and thereby keeping the wound surface dry to be free from infections. In figure 7, all scaffolds showed good swelling ability to retain more water than its own weight. The CMP-incorporated $\mathrm{CH}$ scaffold showed a simultaneous increase in the swelling from the initial time, while PVA scaffold exhibited slow increase in swelling over the time. With this, it is clearly exhibited that CMP makes the scaffold with more swelling capacity than the normal $\mathrm{CH}$ and PVA scaffolds $[22,29,33]$.

\subsection{In vitro degradation studies}

Figure 8 shows in vitro degradation of the $\mathrm{CH}-\mathrm{CMP}$ and PVACMP scaffolds. There were a significant remarkable changes that were observed during the first 2 weeks of degradation. All scaffolds showed a profound swelling after third week. $\mathrm{CH}$ and CMP being natural polymers, show a medium degradation rate when compared with the synthetic PVA scaffold. The increase in the degradation at fourth week is mainly due to the high swelling and loosely bounded CMP to polymer matrix of the scaffold. The chitosan matrix as scaffold in tissue engineering was important because of the gradual degradation of the scaffold within the body than the PVA matrix. Hence, the presence of CMP in the scaffold corresponds to slow degradability and stability $[34,35]$. The advantage of microspheres is that it is incorporated with potent drug into the scaffold in a reduced concentration at the wound site. Moreover, the polymeric microsphere with sustained drug delivery aids in prolonged residence time at the wound site, which was the major role than the direct drug-incorporated scaffold matrix [36].

\subsection{Porosity}

The oxygen permeability of the prepared material is more vital in the wound healing process for the enhanced collagen synthesis and migration of cells. The porosity allows the exchange of oxygen and micronutrients. The porosity of the CH-CMP and PVA-CMP exhibited with liquid displacement method was found to be 75 and $69 \%$, respectively, and is shown in figure 9 . Moreover, the porosity supports the absorption of exudates for easy healing and re-epithelialization [18].

\subsection{In vitro drug release studies}

The release studies of the ciprofloxin HCL-loaded $\mathrm{CH}$ microparticle from the $\mathrm{CH}$ and PVA scaffolds are shown in figure 10. The CH-CMP and PVA-CMP scaffolds showed an initial burst release about 10 and $6.2 \%$, respectively. The initial burst release is mostly preferred for the wound healing. The drawback of the individual drug within the 

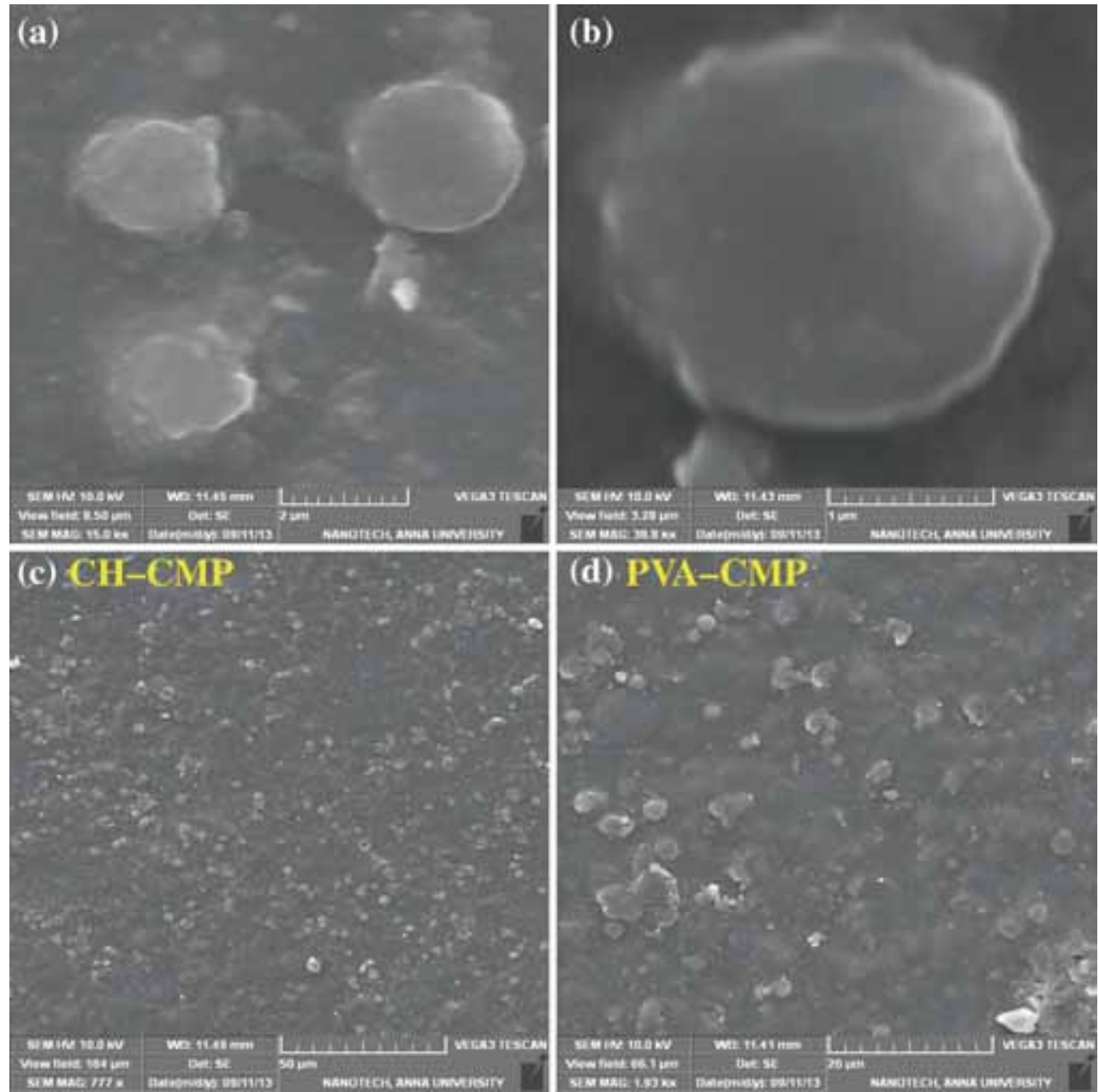

Figure 5. SEM image of CMP at different magnifications: (a) 2, (b) $1 \mu \mathrm{m}$ and (c) $\mathrm{CH}-\mathrm{CMP}$, (d) PVA-CMP scaffolds.

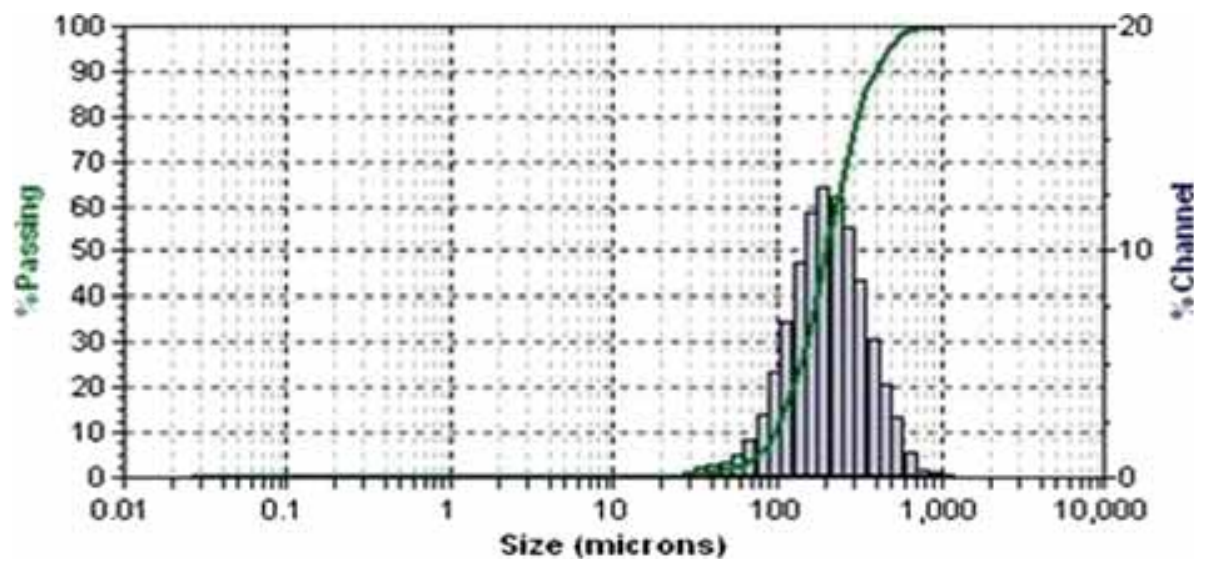

Figure 6. Particle size distribution of the microparticle.

scaffold system was greatly minimized with better release rate achieved through CMP-impregnated scaffold approach. The ciprofloxin HCL-loaded CMP system attains initial burst release due to the non-entrapped drug within the CMP and facilitated sustained drug release to the wound site by keeping it away from infection. At $56 \mathrm{~h}$, maximum $82.7 \%$ release 
Table 2. Tensile properties of scaffolds.

\begin{tabular}{lccr}
\hline Sample no. & Sample name & $\begin{array}{l}\text { Mean tensile } \\
\text { strength (MPa) }\end{array}$ & \multicolumn{1}{c}{$\begin{array}{l}\text { Mean elongation } \\
\text { at break }(\%)\end{array}$} \\
\hline 1 & CH & $8.53 \pm 0.58$ & $19.4 \pm 0.85$ \\
2 & PVA & $9.36 \pm 0.95$ & $23.73 \pm 1.72$ \\
3 & CH-CMP & $7.06 \pm 0.25$ & $16.73 \pm 0.61$ \\
4 & PVA-CMP & $8.03 \pm 1.04$ & $18.6 \pm 0.71$ \\
\hline
\end{tabular}

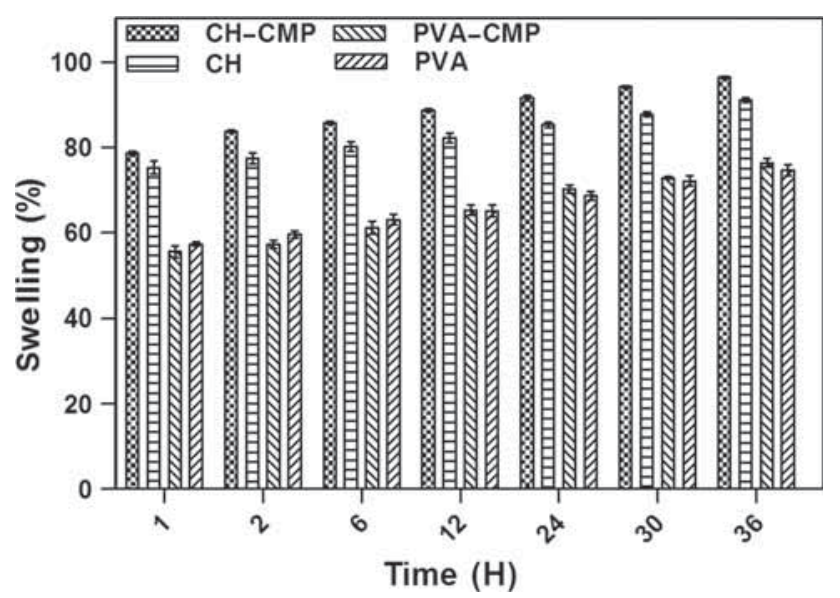

Figure 7. Swelling study behaviour of the scaffolds.

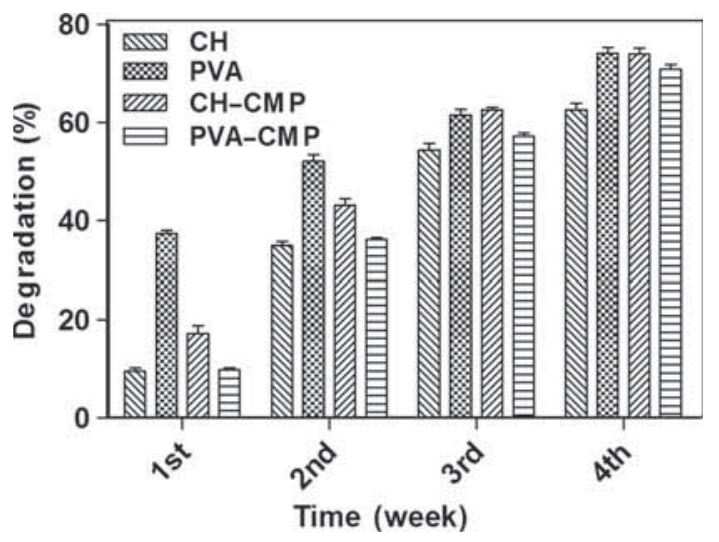

Figure 8. In vitro degradation studies of the scaffolds.

of ciprofloxin HCL from the $\mathrm{CH}$ scaffold was attained due to the easy swelling of both $\mathrm{CH}$ microparticle and scaffold, but the PVA scaffold showed only $70.2 \%$ release, which was attained by the CMP through the scaffold due to the nature of the PVA. The sustained release of drug from the scaffold and CMP was much similar to that of the swelling property of the polymer. The swelling ability of the PVA polymer has decreased the release of drug from the CMP in the PVA-CH scaffold. Overall, both the scaffolds showed a sustained release of drug from the CMP through the system [37-39].

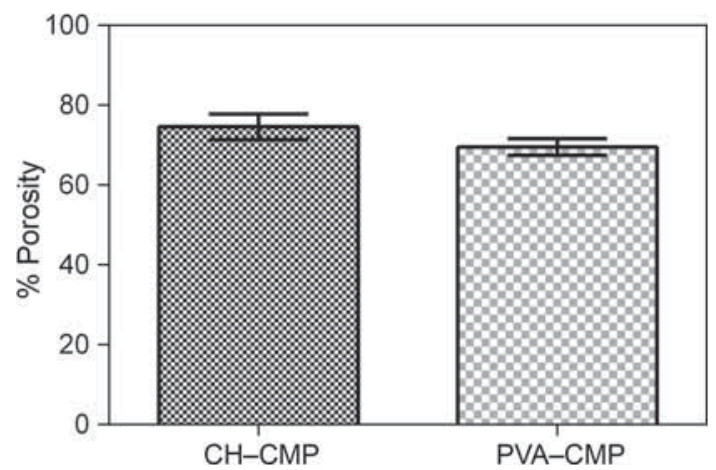

Figure 9. Porosity behaviour of the $\mathrm{CH}-\mathrm{CMP}$ and PVA-CMP scaffolds.

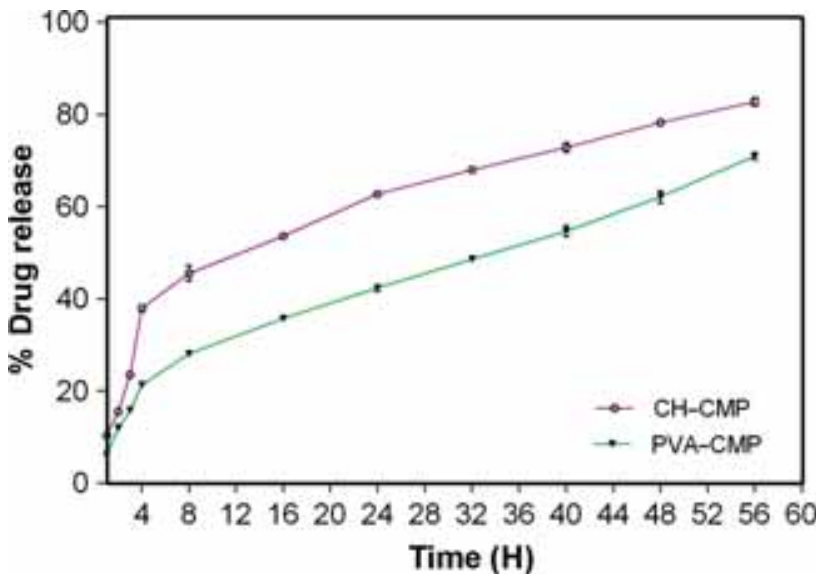

Figure 10. In vitro drug release from the $\mathrm{CH}-\mathrm{CMP}$ and $\mathrm{PVA}-\mathrm{CMP}$ scaffolds.

\subsection{Biocompatibility}

The cell-scaffold interaction is mainly depends on the chemical characteristic of the polymer in the scaffold. The in vitro biocompatibility studies were performed with MTT assay by measuring the growth of NIH $3 \mathrm{~T} 3$ and HACaT cell lines. The scaffolds showed normal morphology when compared with the control. The percentages of cell viability of the scaffolds are given in figure 11a and b. More than $90 \%$ cell viability was observed in both CMP-impregnated scaffolds. The $\mathrm{CH}$ and PVA scaffolds showed more than $85 \%$ of viability. Further, the cell adhesion and the proliferation of the fabricated scaffolds (figure 11c and d) were done for live cells using Calcein AM stain. The CH-CMP scaffold exhibited much more compatibility than the PVA-CMP scaffold. This behaviour could be attributed to the braided morphology of the scaffold. The fibroblast cells will mimic the structure of the extracellular matrix in the submicron environment by facilitating the transfer of nutrients and metabolic wastes, which forms the advantage for the cells to live and function properly $[24,40,41]$. 


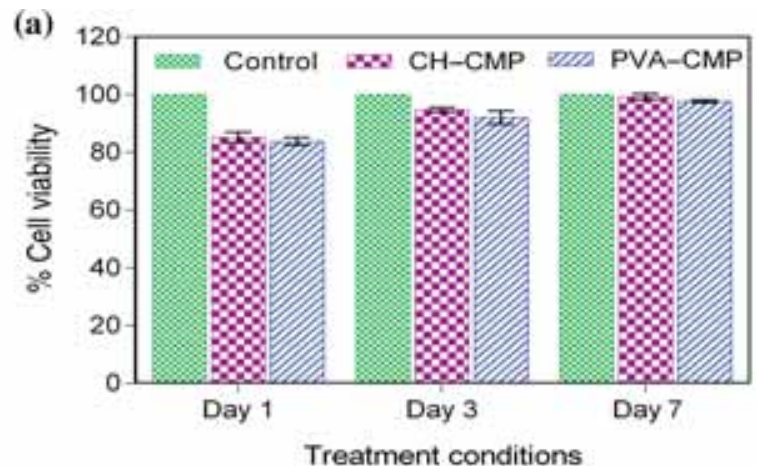

(c)
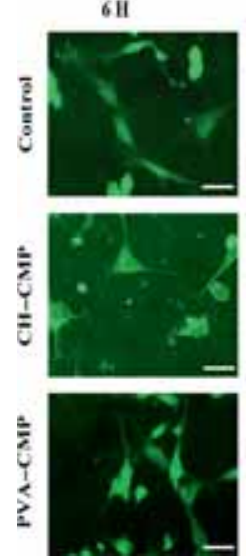

12 H
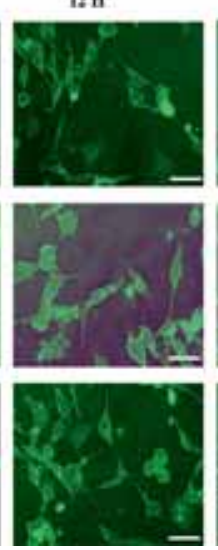

24 II
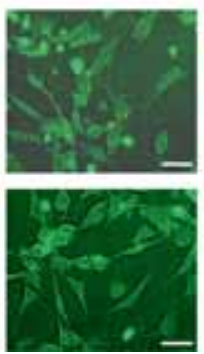

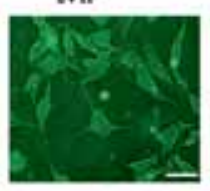

4s H
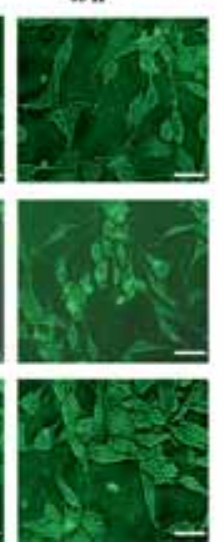

(b)

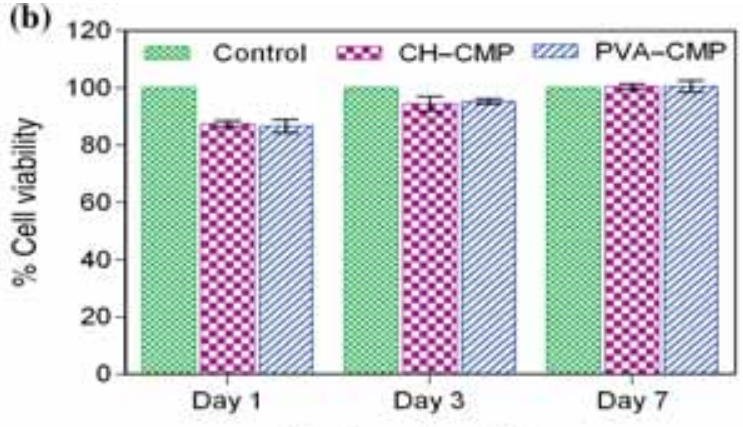

(d)
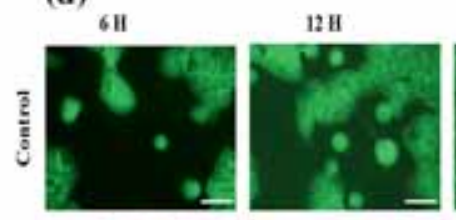

$24 \mathrm{H}$
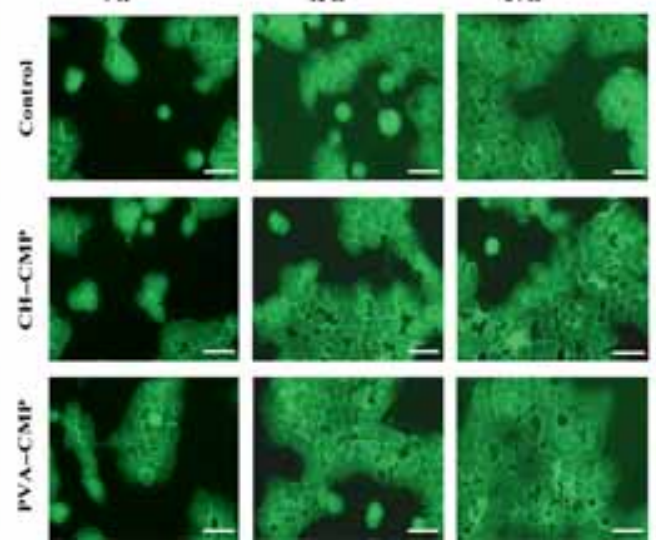

$48 \mathrm{HI}$
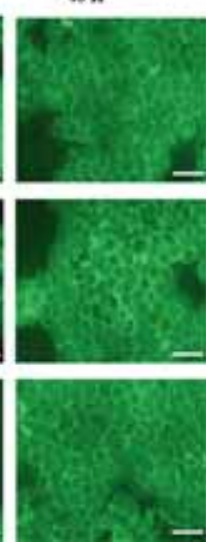

Figure 11. In vitro biocompatibility of the (a) NIH 3 T3 fibroblast and (b) human (HaCaT) keratinocytes cell line over 1, 3 and 7 days using a MTT assay. The data are represented as the mean $\pm \mathrm{SD} ; n=\left({ }^{*} P<0.05\right)$ and in vitro fluorescence staining images of (c) NIH $3 \mathrm{~T} 3$ fibroblast and (d) human (HaCaT) keratinocytes cell adherence and proliferation onto the CH-CMP and PVA-CMP scaffolds in comparison to the control at $6,12,24$ and $48 \mathrm{~h}$. The scale bar is $100 \mu \mathrm{m}$.
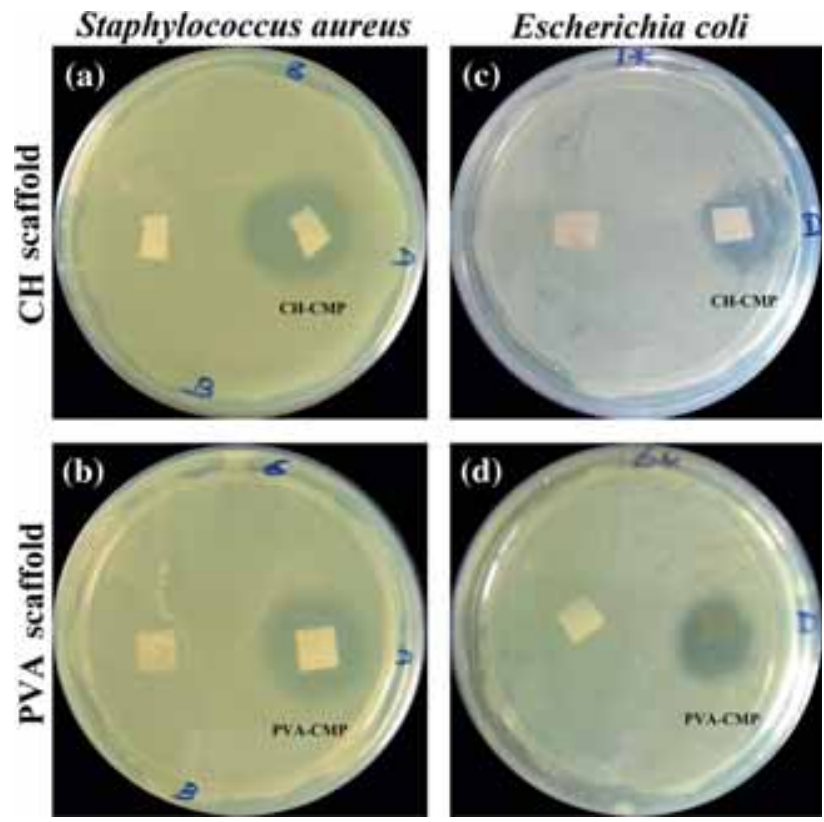

Figure 12. Antimicrobial activity of the $\mathrm{CH}-\mathrm{CMP}$ and PVA-CMP scaffolds: (a, b) S. aureus and (c, d) E. coli. 3.9a Antimicrobial activity: Antimicrobial activity of the CH-CMP and PVA-CMP scaffolds were assessed with both Gram-positive $S$. aureus and Gram-negative Esherichia coli bacterial strains. The presence of the drug-loaded microparticle exhibits clear zone of inhibition when compared to that of the normal scaffold without drug. The zones of inhibition of the scaffolds are depicted in figure 12. The clear zone implies that the release of drug will inhibit the infection from the wound site and finds its way in wound healing applications $[18,26]$.

\section{Conclusion}

As described, ciprofloxin HCL-loaded $\mathrm{CH}$ microparticles were impregnated in both natural and synthetic scaffolds, which were comparatively studied to make efficient biomaterial for the release of drug onto the wound site. The scaffolds exhibited competent thermal properties with better swelling and tensile strength. From the swelling studies, in vitro degradation and tensile strength were found to be more selective in choosing the appropriate material. In comparison, 
CH-CMP scaffold proved to exhibit better biocompatibility when compared with the PVA-CMP scaffold. On the other hand, the efficient release of drug from the $\mathrm{CH}-\mathrm{CMP}$ scaffold provides a strong evidence to prefer this material, which is more suitable for tissue engineering. Hence, $\mathrm{CH}-\mathrm{CMP}$ scaffold would be an optimal choice of scaffold found to be more suitable for the drug delivery in tissue engineering application.

\section{Acknowledgements}

We acknowledge CSIR-CLRI for providing the funds and infrastructure to carry out this study. Financial support from CSIR under Translational Project OLP-09/TRP is acknowledged. We sincerely thank the Director, Centre for Nanoscience and Technology, Anna University, for helping us in availing the SEM facility.

\section{References}

[1] Sionkowska A and Płanecka A 2013 J. Mol. Liq. 1785

[2] Croisier F and Jerome C 2013 Eur. Polym. J. 49780

[3] Yu X, Bichtelen A, Wang X, Yan Y, Lin F, Xiong Z et al 2005 J. Bioact. Compat. Pol. 2015

[4] Sogias I A, Williams A C and Khutoryanskiy V V 2008 Biomacromolecules 91837

[5] Hsu S-H, Chang Y-B, Tsai C-L, Fu K-Y, Wang S-H and Tseng H-J 2011 Colloid Surf. B 85198

[6] Rinaudo M 2006 Prog. Polym. Sci. 31603

[7] Cai Z-X, Mo X-M, Zhang K-H, Fan L-P, Yin A-L, He C-L et al 2010 Int. J. Mol. Sci. 113529

[8] Felt O, Buri P and Gurny R 1998 Drug Dev. Ind. Pharm. 24 979

[9] Nakorn P N 2008 J. Min. Met. Mat. S. 1873

[10] Choi Y, Nirmala R, Lee J Y, Rahman M, Hong S-T and Kim H Y 2013 Ceram. Int. 394937

[11] Bai J, Li Y, Yang S, Du J, Wang S, Zheng J et al 2007 Solid State Commun. 141292

[12] Chun W, Xiong F and Liansheng Y 2007 Chinese Sci. Bull. 52 883

[13] Tao Y, Lu Y, Sun Y, Gu B, Lu W and Pan J 2009 Int. J. Pharm. 37830

[14] Vergaro V, Scarlino F, Bellomo C, Rinaldi R, Vergara D, Maffia M et al 2011 Adv. Drug Deliv. Rev. 63847

[15] Harris R, Lecumberri E, Mateos-Aparicio I, Mengibar M and Heras A 2011 Carbohydr. Polym. 84803

[16] Bendix K, Johann J, Gudbergsson M, Skov M N, Pilgaar L, Moos T et al 2014 Biochim. Biophys. Acta 184675
[17] Dustgania A, Farahani E V and Imani M 2008 Iran J. Pharm. Sci. 4111

[18] Muthukumar T, Senthil R and Sastry T P 2013 Colloid Surf. B 102694

[19] Ali S W, Rajendran S and Mangala Joshi M 2011 Carbohydr. Polym. $\mathbf{8 3} 438$

[20] Jia Y-T, Gong J, Gu X-H, Kim H-Y, Dong J and Shen X-Y 2007 Carbohydr. Polym. 67403

[21] Kumar V, Koltypin Y, Cohen Y S, Cohen Y, Aurbach D, Palchik $\mathrm{O}$ et al $2000 \mathrm{~J}$. Mater. Chem. 101125

[22] Ramanathan G, Singaravelu S, Raja M D, Liji Sobhana S S and Sivagnanam U T 2014 J. Biomater. Tissue Eng. 4203

[23] Nagiah N, Ramanathan G and Sivagnanam U T 2013 Polym. Tech. 3221370

[24] Nagiah N, Ramanathan G, Liji Sobhana S S, Sivagnanam U T, Srinivasan N T 2013 Int. J. Polym. Mater. 63583

[25] Devendiran R M, Chinnaiyan S K, Mohanty R K, Ramanathan G, Singaravelu S, Liji Sobhana S S et al 2014 J. Biomater. Tissue Eng. 4430

[26] Ramanathan G, Singaravelu S, Raja D, Nagiah N, Padmapriya P, Ruban K et al 2016 RSC Adv. 67914

[27] Kandhasamy S, Ramanathan G, Kamalraja J, Balaji R, Mathivanan N, Sivagnanam U T et al 2015 RSC Adv. 555075

[28] Sudhamani S R, Prasad M S and Udaya Sankar K 2003 Food Hydrocoll. 17245

[29] Dudhani A R and Kosaraju S L 2010 Carbohydr. Polym. 81 243

[30] Archana D, Dutt J and Dutta P K 2013 Int. J. Biol. Macromol. 57 193

[31] Rokhade A P, Agnihotri S A, Patil S A, Mallikarjuna N N, Kulkarni P V and Aminabhavi T M 2006 Carbohydr. Polym. 65 243

[32] Barroso T, Viveiros R, Casimiro T and Aguiar-Ricardo A 2014 J. Supercrit. Fluid. 94102

[33] Lee Y M, Kim S H and Cho C S 1996 J. Appl. Polym. Sci. 62 901

[34] Liu Y, Vrana N E, Cahill P A and McGuinness G B $2009 \mathrm{~J}$. Biomed. Mater. Res. B Appl. Biomater. 90492

[35] Costa-Pinto A R, Martins A M, Castelhano-Carlos M J, Correlo V M, Sol P C, Longatto-Filho A et al 2014 J. Bioact. Compat. Pol. 29137

[36] Ramteke K H, Jadhav V B and Dhole S N 2012 IOSR J. Pharm. 244

[37] Panyam J, Dali M M, Sahoo S K, Ma W, Chakravarthi S S and Amidon G L 2003 J. Control. Release 92173

[38] Kim C J and Lee P I 1992 Pharm. Res. 910

[39] Huang X, Du Y-Z, Yuan H and Hu F-Q 2009 Carbohydr. Polym. 76368

[40] Neamnark A, Sanchavanakit N, Pavasant P, Rujiravanit R and Supaphol P 2008 Eur. Polym. J. 442060

[41] Zhou G, Ruhan A, Heng G, Wang L, Liu M, Wang B et al 2014 Burns 401668 